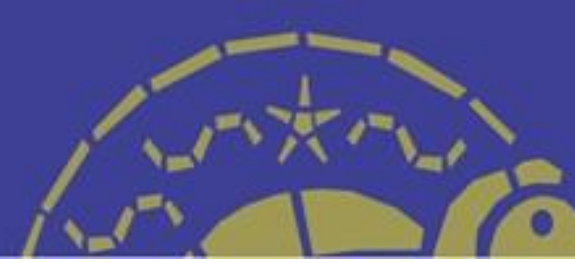

\title{
DO GABINETE À COMUNIDADE: A EXPERIÊNCIA DO PROJETO RONDON NA FORMAÇÃO PROFISSIONAL NO CAMPO DE PÚBLICAS
}

\author{
Sonia Maria Martins Passos \\ tsonm.passos@ig.com.br \\ Fernanda Santos de Souza Ayres \\ nandasouzabib@yahoo.com.nr \\ Breno de Paula de Andrade Cruz \\ brenocruz@ufrrj.br
}

\begin{abstract}
Nathália Cândido da Silva nathaliacandido@hotmail.com

Sabrina Gomes dos Santos sabrina.g.santos@hotmail.com
\end{abstract}

Resumo

O objetivo deste artigo é problematizar o alinhamento da matriz curricular de um curso do Campo de Públicas à extensão universitária, usando como objeto de análise o Projeto Rondon. Por meio de um Estudo de Caso Descritivo (Yin, 2005) analisa-se por meio de uma análise documental e entrevistas em profundidade com discentes autores da proposta aprovada no edital do Projeto Rondon (Janeiro 2015), a aderência do conteúdo técnico e profissional no curso de graduação de uma instituição de ensino superior pública federal às demandas do mercado de trabalho - especificamente temas relacionados à Saúde, Educação, Cultura, Direitos Humanos e Justiça. Os resultados apresentados neste artigo evidenciam a importância dos elementos presentes na matriz curricular do curso analisado na construção de ações que fomentem a implementação de políticas públicas em temas relacionados à Saúde, Educação, Cultura, Direitos Humanos e Justiça, aproximando o futuro profissional ao campo de trabalho.

Palavras-chave: Extensão Universitária. Campo de Públicas. Projeto Rondon

\section{OFFICE OF THE COMMUNITY: THE EXPERIENCE OF THE RONDON PROJECT IN VOCATIONAL TRAINING IN PUBLIC COURSE}

Abstract

This study's goal is to problematize the alignment of a graduation course Public Partition's curriculum to the university extension section using the Rondon Project as an object of analysis. Through a Descriptive Case Study (2005, Yin) is found athwart a documental analysis and massive interviews with authorial students from the approved proposition in the Rondon Project's (2015, January) notice the adherence of the technical and professional content in the graduation course from a public federal institution of higher education to the demands from the labor market - specifically Health, Education, Culture, Human Rights and Justice related themes. The results presented in this article show important evidence from the existing elements in the analyzed graduation course's curriculum when considering the constructive actions that promote the insertion of public policies in Health, Education, Culture, Human Rights and Justice related themes, approaching the profissional future with the labor market.

Keywords: University Extension Programs. Pública Field. Rondon Project

\section{OFICINA DE LA COMUNIDAD: LA EXPERIENCIA DEL PROYECTO RONDON EN LA FORMACIÓN PROFESIONAL EN EL CAMPO PÚBLICO}

Resumen

El propósito de este artículo es discutir la alineación del plan de estudios de un curso de campo de la extensión universitaria pública, utilizando como objeto de análisis del Proyecto Rondon. A través de un estudio descriptivo del caso (Yin, 2005) se analizaron mediante un análisis de documentos y entrevistas con autores estudiosos de la propuesta aprobada en el anuncio del Proyecto Rondon (enero de 2015) la adherencia del contenido técnico y profesional en el curso graduado de una institución pública federal de educación superior a las demandas del mercado de trabajo - concierne 
específicamente a la Salud, educación, Cultura, derechos Humanos y Justicia. Los resultados presentados en este artículo muestran la importancia de los elementos presentes plan de los estudios analizados en la construcción de acciones que fomenten la aplicación de políticas públicas en temas relacionados con la Salud, Educación, Cultura, Derechos Humanos y Justicia, con lo que el futuro campo de trabajo profesional.

Palavras clave: Extensión Universitaria. Campo público. Proyecto Rondon 
Do gabinete à comunidade: a experiência do Projeto Rondon na formação profissional no campo de públicas

\section{INTRODUÇÃO}

O ensino em Administração no Brasil por vezes apresentou uma lacuna entre teoria e prática (Graça; Botelho, 2013, p. 3). Especialmente nas instituições federais públicas, em que por anos se encontravam professores e pesquisadores reconhecidos na pesquisa em Administração e áreas afins, esta lacuna pareceu prevalecer quando comparada às instituições privadas que muitas vezes tinham como foco a preparação dos estudantes para o mercado de trabalho. No Campo de Públicas, a Extensão Universitária pode se construir como uma estratégia eficiente para que lacunas ou este distanciamento entre teoria e prática sejam minimizadas.

É neste contexto governamental de mudança e neste contexto acadêmico de crescimento e diversificação da formação de pesquisadores e profissionais que, a partir dos anos 2000, se dá o surgimento do "Campo de Públicas" (Pires et. al. 2014) enquanto um movimento voltado, inicialmente, à autonomização da disciplina de Administração Pública, e, posteriormente à construção de uma identidade de "projeto" que dará sustentação para rumar no sentido de constituir-se em uma Comunidade Científica hoje conhecida por "Campo de Públicas".

A curricularização da Extensão Universitária, conforme Lei de Diretrizes e Bases da Educação Nacional de 1996 e o Programa de Extensão Universitária (PROEXT) - Decreto-Lei n. 6.495/2008, é uma realidade nas instituições de ensino superior no Brasil ao possibilitar um alinhamento entre a aplicação dos conhecimentos produzidos nas diversas universidas (não somente as públicas) às demandas do cidadão e da sociedade. Em outras palavras, o conhecimento produzido pode estar acessível à população. Especificamente para professores e alunos do Campo de Públicas, o alinhamento da teoria à prática por meio da Extensão Universitária tem demonstrado em algumas experiências (CRUZ et al., 2012) a importância dessas ações na formação dos discentes e dos professores, além de gerar impactos positivos para as populações que são beneficiadas pelos conjuntos de ações desenvolvidas pelos grupos extensionistas no Campo de Públicas.

Como ressalta Romano (1998, p. 15), a Universidade deve “ir onde o povo está", isto é, buscar a sociedade, colocar-se em contato efetivo e permanente com ela, torná-la ator principal da própria dinâmica universitária. Na prática, em especial no Campo de Públicas, a abordagem do recente modelo de gestão tem sido debatido. O conceito de Gestão Social é uma abordagem ajustada por uma gestão universitária da extensão legitimada pela dialogicidade, ou seja, em permitir aos alunos agir e refletir sobre a ação pedagógica realizada, a cidadania com tomada de decisão e a criação de espaços democráticos de participação, para que possam exercer uma nova relação Universidade e Sociedade sob uma "Nova Administração Pública" e "[...] um sistema político e administrativo mais sensível e responsável ante às necessidades dos cidadãos [...]”, 
Do gabinete à comunidade: a experiência do Projeto Rondon na formação profissional no campo de públicas

construída no "engajamento ético [...] do cientista social", e do próprio Administrador Público (RAMOS, 1983a, p. 39).

Desde a década de 1960 o Projeto Rondon vem possibilitando que universidades brasileiras possam implementar ações extensionistas em regiões com demandas sociais e econômicas. As instituições são levadas para áreas extremamente necessitadas de diversas políticas públicas e lá estudantes de diversos cursos compartilham seus conhecimentos com a população e (re)constroem suas visões de mundo e de atuação profissional.

O objetivo deste artigo é apresentar os resultados da elaboração da proposta do Projeto Rondon por alunos e professores de um curso do Campo de Públicas, de uma IES pública evidenciando como a Extensão Universitária e a formação dos discentes possibilita, respectivamente, a Extensão Universitária como parte do processo de ensino-aprendizagem; e, a aderência do conteúdo abordado durante o curso à elaboração de uma proposta vencedora em um edital que envolveu instituições de todo o país. Especificamente, pretende-se: (i) problematizar a Extensão Universitária no Campo de Públicas; (ii) evidenciar que estudantes de um curso do Campo de Públicas, mediante disciplinas presentes na matriz curricular, estão preparados para concorrerem em editais competitivos - como o do Projeto Rondon; (iii) e que as experiências obtidas na implementação das ações pensadas por eles no campo trazem uma experiência profissional e pessoal marcante nas possibilidades futuras de elaboração ou avaliação de políticas públicas.

Neste sentido, esse trabalho se torna relevante por problematizar a extensão universitária no Campo de Públicas, além de poder servir de inspiração para outros discentes e docentes na elaboração de futuras propostas. O artigo está assim estruturado: a próxima seção apresenta, de maneira breve, algumas características gerais do contexto histórico do surgimento do Campo de Públicas, instituído pela Resolução No. 1, de 13 de janeiro de 2014. O terceiro item do artigo discute a Extensão Universitária e o Projeto Rondon, sendo seguido na próxima seção da Metodologia - apresentando as características de um Estudo de Caso. A quinta seção apresenta e discute os resultados; e, por fim, o sexto item apresenta algumas limitações do estudo e questões para futuras pesquisas.

\section{O CAMPO DE PÚBLICAS}

A partir de 1995, a reforma gerencial no Brasil surgia buscando, sobretudo, a oferta de serviços públicos de qualidade e maior eficiência na Administração Pública brasileira. A qualidade pretendida com a reforma seria conquistada com a desburocratização dos sistemas de gestão 
Do gabinete à comunidade: a experiência do Projeto Rondon na formação profissional no campo de públicas

pública e com o destaque na atuação por desempenho e, por meio disso, angariar a satisfação do cidadão (Bresser-Pereira, 1999, p. 05 e 06).

No que concerne o quesito eficiência, este não caberia em somente suprimir os gastos do governo, mas, saber usá-los de forma mais adequada, evitando as despesas desnecessárias. Para subsidiar estas propostas oriundas do governo de Fernando Henrique Cardoso, um ponto fundamental que era a contratação de pessoal especializado, altamente capacitado, também foi pensado (Plano Diretor de Reforma do Aparelho do Estado, 1995, p. 25).

Apesar de a reforma não ter obtido êxito total em suas propostas iniciais, sem dúvida, foi um fator marcante em meio a diversas mudanças que aconteceram no Estado pós-período de governo militar, em um ambiente onde a democracia tornara a assumir seu protagonismo e, os resquícios de sua investidura perduram até hoje. Em virtude das crises e tranformações de Estado enfrentadas no Brasil nos últimos 25 anos, ocorreram diversas alterações na demanda dos profssionais do setor público do país. Por isso, na década de 2000 houve um grande aumento na oferta dos cursos de graduação na marcro-área de gestão pública. ( Pires et al,2014, p. 112).

Este campo no qual Pires et al. (2014) se referem é o denominado Campo de Públicas que reúne um vasto terreno de conhecimentos voltados para gestão da coisa pública e abrange cursos de ensino superior, como Administração Pública (AP), Gestão Social, Gestão Pública, Políticas Públicas, Gestão Pública para o Desenvolvimento Econômico Social e Gestão de Políticas Públicas. Conforme apontam os autores, esta área de conhecimento, se originou de uma mobilização do curso de graduação em Administração Pública que muito lutou para a consolidação de sua identidade, pois, a mesma era considerada um ramo do curso de administração de empresas.

Coelho (2008) problematizou que em 1995 - ano em que se iniciou a reforma gerencial o Brasil tinha cerca de treze cursos de graduação em Administração Pública devidamente registrada nos junto ao Conselho Federal de Educação. Todavia, estes cursos "eram cursos de graduação em Administração com habilitação em AP. De acordo com o autor, essa área de conhecimento só cresceu após o ano de 1995 - visto que na década de 1980 o ensino superior em AP tinha sido enfraquecido. Contudo, com a reforma do Estado e com o surgimento ideolólico da Nova Administração Pública, essa formação acadêmica cresceu novamente em função de um macroambiente favorável a gestão pública (Coelho, 2008).

Parte desse ganho também é atribuído às diversas mobilizações em prol do reconhecimento das particularidades existentes entre os cursos do Campo de Públicas e os cursos de administração empresarial, em especial, o I Encontro Nacional dos Estudantes de 
Do gabinete à comunidade: a experiência do Projeto Rondon na formação profissional no campo de públicas

Administração Pública realizado em 2002 e III Encontro Nacional sobre Diretrizes Curriculares para os Cursos de Graduação em Administração, em 2005.

No mesmo ano, o Conselho Federal de Administração e a Angrad emitiram um comunicado nacional definindo a existência das denominações dos cursos de Administração e Administração Pública. No mesmo sentido, foi publicado no ano subsequente, um despacho do Diretor do Departamento de Supervisão do Ensino Superior do Ministério da Educação, estabelecendo a distinção dos cursos de Administração e Administração Pública. Com esse suporte institucional, a partir de 2004, novos cursos de administração pública foram surgindo. Esses encontros também foram considerados como progenitores do Campo de Públicas (PIRES et al. 2014, p. 114).

\section{EXTENSÃO UNIVERSITÁRIA E O PROJETO RONDON}

O Projeto Rondon é uma homenagem ao Marechal Cândido Mariano da Silva. Num contexto de ditaduras na América Latina, o Movimento Estudantil nos anos 60 e 70 e a prática de uma Extensão Universitária libertadora passou a ser compreendida como exercício de risco ao regime militar no Brasil (Serrano 2010 p. 08). Neste contexto histórico, Vieira, (2014, p. 62), considera o Projeto Rondon na época da ditadura como forma de se contrapor e cooptar os estudantes para o trabalho assistencial comunitário.

Para Nogueira (2001, p. 60) o Projeto consistia, à época, em “(...) uma proposta inserida ao ideal de Desenvolvimento e Segurança, em que os alunos eram apenas executores". Os referidos autores descrevem seu surgimento como um movimento de ação sócio comunitário e institucional, que em sua natureza institucional tinha o vício de não ser vinculada as universidades e sua prática sócio comunitária não era organizada, nem sistêmica, os estudantes eram conduzidos a perceber apenas parte da realidade trabalhada e não fundamentar vínculos mais duradouros e concretos com a região ou localidade.

A ideia do Projeto Rondon havia surgido em 1966, na Escola de Comando e EstadoMaior do Exército, sendo criado em 1967, durante a ditadura militar, como resultado de uma pesquisa sociológica desenvolvida pela Universidade do então Estado da Guanabara, atual Universidade do Estado do Rio de Janeiro (UERJ), e da Escola de Comando e Estado-Maior do Exército.

O Projeto Rondon tinha como slogan"integrar para não entregar", expressando num conjunto de ideias desenvolvimentista vinculado à doutrina de segurança nacional. Trinta 
Do gabinete à comunidade: a experiência do Projeto Rondon na formação profissional no campo de públicas

estudantes e dois professores seguiram do Rio de Janeiro para Rondônia em uma aeronave C-47, oferecida pelo antigo Ministério do Interior. A equipe por 28 dias ficou na localidade realizando trabalhos de levantamento, pesquisa e assistência médica.

Flanklin (2012) descreve que o Projeto Rondon foi idealizado no período dos Governos Militares, iniciando por Costa e Silva (1967-1969) a João Batista de Figueiredo (1979-1985). O Governo do Presidente Geisel (1974-1979) teve o objetivo de avivar o projeto, dotando-o de recursos para que pudesse assegurar uma participação maior dos estudantes no processo de desenvolvimento social e econômico do País. Os Ministérios envolvidos na ocasião foram do: Interior, Educação e Cultura, Saúde e Comunicações.

Somente com o retorno do Projeto Rondon em meados da primeira década do século XXI é que de fato a proposta se aproxima aquilo que propõe Paulo Freire, deixando de ser uma estratégia de doutrinação conforme apontam os autores supracitados, atuando, assim, de maneira a multiplicar conhecimentos por meio da extensão universitária.

A proposta de uma extensão no exercício de um processo transformador, libertador e democrático; acrescida, de uma extensão desenvolvida no diálogo e no respeito à cultura local, nos autoriza constatar quanto o pensamento freiriano foi significativo e importante e está inserido no conceito da extensão das universidades públicas brasileiras, como descreve: “ $\mathrm{O}$ conhecimento não se estende do que se julga sabedor até àqueles que se julga não saberem; o conhecimento se constitui nas relações homem-mundo, relações de transformação, e se aperfeiçoa na problematização crítica destas relações" (Freire, 2006, p.36).

A extensão universitária é um instrumento para os discentes para a troca de experiências, implementação de teorias na prática, de forma horizontal, discentes e comunidade, a fim de construir com a sociedade o desenvolvimento local. Com um novo slogan "lição de vida e cidadania", em 19 de janeiro de 2005 o Projeto Rondon foi retomado pelo governo federal, mais de quinze anos depois de sua extinção, em Tabatinga (AM), a pedido da União Nacional dos Estudantes (UNE); já sendo, desde o retorno 778 municípios já foram beneficiados e ainda 272 IES - Instituições de Ensino Superior promoveram 137 ações, através de 17.300 rondonistas (Ministério da Defesa, 2014).

O Projeto Rondon “direciona professores e alunos universitários (rondonistas) de diferentes cursos de graduação para suas ações nos municípios selecionados que em parceria com as lideranças locais atuam na melhoria da qualidade de vida das localidades e ainda na implementação da eficiência da administração municipal".

Saraiva (2007) enfatiza que atualmente a extensão universitária é primordial para assegurar o cunho social da universidade de formar cidadãos comprometidos com a sociedade na qual 
Do gabinete à comunidade: a experiência do Projeto Rondon na formação profissional no campo de públicas

vivem, e formando profissionais capacitados que promovam o diálogo evolutivo e positivo na construção, dos saberes populares com os conhecimentos técnico e científico, valorizando a diversidade sociocultural das regiões brasileiras e apoderar das tecnologias sociais pelas comunidades.

$\mathrm{Na}$ atual conjuntura brasileira de gestão onde se discute e introduz a sociedade para a tomada de decisão no exercício da cidadania, o processo de desenvolvimento que se deseja para o país é mobilizado por organizações que trabalham juntas ou por interorganizações cuja principal característica é a hibridização ou a complexidade (Fischer, 2002). Assim, o conceito de Gestão Social tem se consolidado enquanto prática, sem ainda o consenso sobre o conceito (Pinho, 2010). E dentro desta nova filosofia que demanda a sociedade, ações como o Projeto Rondon ganham destaque pela adequação, interação com as instituições e a sociedade. Paes de Paula (2005, p. 39), considera a Administração Pública como um modelo de gestão social que procura atender aos interesses nacionais. E ao se construir instituições políticas e políticas públicas voltadas para as necessidades dos cidadãos, conforme aponta a autora, entende-se que a extensão universitária por meio do Projeto Rondon, pautada no pensamento Freiriano, se constitui como uma robusta intervenção na perspectiva do desenvolvimento local e nacional.

\section{MATERIAL E MÉTODOS}

Este trabalho possui características qualitativas ao demonstrar a experiência das alunas do Campo de Públicas de uma IFES, na elaboração da proposta submetida ao Projeto Rondon, bem como a importância do projeto para os discentes da IFES, para o curso de Administração Pública e para o Campo de Públicas. A equipe da IFES em análise foi composta por dois professores e quatro alunas do Campo de Públicas, uma aluna do curso de Pedagogia, uma aluna de Agronomia e dois alunos de Ciências Biológicas. O conjunto de ações desenvolvidas foi do Conjunto A - Educação, Cultura, Saúde, Direitos Humanos e Justiça. A equipe composta por dois professores e oito estudantes representa não um curso e sim a IFES (que possui mais de 50 cursos de graduação e mais de 100 anos de existência).

No que diz respeito ao método científico que estrutura esta investigação, este trabalho utilizao Estudo de Caso. Quanto à natureza do Estudo de Caso, ele se caracteriza como um Estudo de Caso Descritivo, uma vez que descreve de maneira aprofundada o contexto, as ações, atores ou interação entre estes (YIN, 2005). O Estudo de Caso em questão, não possui caráter 
Do gabinete à comunidade: a experiência do Projeto Rondon na formação profissional no campo de públicas

conclusivo, visto que, o mesmo pretende apenas descrever a experiências das estudantes do Campo de Públicas.

Quanto às técnicas utilizadas na coleta de dados, foram utilizadas: (i) análise documentale (ii) entrevistas com as discentes envolvidas na realização da proposta submetida ao Projeto Rondon e com os professores responsáveis naquela operação. A análise documental foi realizada com base no projeto que fora enviado para a coordenação do Projeto Rondon, bem como pelos relatórios das ações desenvolvidas no município em que a IFES foi direcionada.

Uma vez coletados os dados por meio da análise documental e das entrevistas em profundidade, buscou-se as categorias emergentes a partir destes dados por meio da Análise de Conteúdo (VERGARA, 2005). As categorias são apresentadas a seguir na próxima seção.

\section{RESULTADOS E ANÁLISE}

\section{Sim, estamos preparadas para competir!}

Há oito anos a IFES aqui analisada não participava do Projeto Rondon. Por isso, alguns dos seus atuais alunos não conheciam a proposta, a exemplo do alunos de uma das turmas de Administração Pública e de outros cursos da área de Ciências Sociais Aplicadas. Duas alunas tiveram conhecimento do Rondon em sala de aula na disciplina Cidadania e Inclusão Social e se propuseram a ir além da sala de aula considerando a grandiosidade e relevância do projeto.

Segundo as alunas, a motivação surgiu a partir da percepção de que seria possível utilizar os ensinamentos adquiridos em algumas disciplinas na elaboração da proposta do Projeto Rondon. No contato com as disciplinas Gestão de Projetos Públicos, Políticas Públicas e Sociedade, Elaboração de Políticas Públicas, Projetos de Cidadania e Inclusão Social foi possível verificar que os pontos do edital estavam consonantes aos aspectos encontrados naquelas disciplinas. Conforme as alunas, "as disciplinas são dinâmicas e enriquecedoras e por meio delas, os discentes aprendem passo a passo, como elaborar projetos públicos e políticas públicas a partir de um problema apresentado”. O Projeto Rondon seria uma forma delas colaborarem para o bem estar de uma população carente no estado da Paraíba (PB) e também perceberam o quanto essa experiência enriqueceria suas formações profissionais aposteriori.

Confiando na implementação de suas ideias e dos conhecimentos construídos em sala de aula com os professores do curso, as discentes procuraram um de seus professores para orientálas. Conforme o professor, "embora o prazo fosse curto, eu não teria o direito de dizer um não e 
Do gabinete à comunidade: a experiência do Projeto Rondon na formação profissional no campo de públicas

acabar com aquele sonho. Eu também era marinheiro de primeira viagem no Rondon, mas eu tinha a obrigação de dizer um sim e motivá-las". Assim, o professor aceitou a proposta como uma forma de motivá-las, visto que o trabalho voluntário e a experiência em campo são essenciais na formação dos discentes do Campo de Públicas.

As discentes enviaram para o professor uma primeira versão do projeto que, segundo ele, superou suas expectativas. Desta maneira, o docente colaborou com o aperfeiçoamento técnico e acadêmico da proposta, questionando as propostas, as ações, os aspectos metodológicos, técnicos, teóricos e estruturais. Um esforço mútuo foi realizado por parte das discentes e do docente, seja na elaboração do documento ou até mesmo questões burocráticas da Pró-Reitoria a qual a proposta deveria estar vinculada. O resultado de todo o esforço inicial foi a aprovação da proposta.

A aprovação do projeto despertou nas alunas um sentimento de dever cumprido pois elas sabiam que suas ações trariam um importante retorno para a sociedade. Diante disso, observouse que a matriz curricular do curso de Administração Pública, parece estar alinhada às demandas do setor público ao capacitar suas discentes a competirem com professores de outras IES na elaboração de uma proposta de projeto público.

Nos primeiros três períodos, o discente tem contato com disciplinas que fornecerão conhecimentos básicos sobre gestão, são estas: Introdução a Administração, Contabilidade Geral I e II, Introdução a Administração Pública, Psicologia aplicada à Administração, Noções de Direito Público e Privado e Direito Administrativo; Conhecimentos que fomentarão a capacidade crítica do aluno em pensar sociedade são disseminados no decorrer do ensino das disciplinas de Sociologia aplicada à Administração e Antropologia Social. Em relação ao desenvolvimento da inteligência lógico-matemática, que será requisitada principalmente no eixo de orçamentação e gestão de finanças públicas, ele entra em contato com matérias como: Matemática I, Matemática Financeira, Estatística Básica, Fundamentos de Macroeconomia e Microeconomia e, Teoria da Contabilidade de Custos.

A experiência de elaboração e implementação das ações no município foram muito enriquecedoras para discentes e docentes. Hoje, observamos que, os discentes envolvidos não estão preparados apenas para elaborarem um projeto como este, mas também, estão preparados para encontrar uma realidade distinta das suas, e, diante do que for analisado, realizarem propostas de melhorias para a comunidade em questão.

Por isso, o Projeto Rondon fornece aos universitários uma experiência que agrega grande valor ao futuro profissional, principalmente para os profissionais do Campo de Públicas, já que este campo de atuação visa e discute questões de interesse público. A experiência de pensar a 
Do gabinete à comunidade: a experiência do Projeto Rondon na formação profissional no campo de públicas

Elaboração de Políticas Públicas in lócus foi a maior experiência adquirida, visto que muitas críticas em relação à elaboração de Políticas Públicas se constroem em função da distância do elaborador das políticas públicas do público que ele pretende atingir.

\section{A Implementação das Ações}

As ações implementadas pela equipe representaram o Conjunto de Ações A: - Educação, Cultura, Saúde, Direitos Humanos e Justiça, e foram direcionadas a diversos públicos como crianças, adolescentes, professores, gestores, agricultores e à comunidade em geral. Foram trabalhados temas como drogas, diversidade sexual, gravidez precoce, sustentabilidade e uso racional de recursos na esfera pública (A3P), elaboração de projetos públicos e participação social.

Dentre as mais de 50 atividades desenvolvida pela IFES nos 18 dias de inserção da equipe em um município do agreste paraibano, escolhemos algumas que são aqui apresentadas e que estão relacionadas ao Campo de Públicas. Começando pelo eixo dos Direitos Humanos e Justiça, foi oferecida aos gestores do município uma oficina que abordou sobre os conselhos municipais e a elaboração de projetos públicos. Essa atividade promoveu o debate sobre a formação e o funcionamento dos conselhos e as consequentes diferenças entre o que diz a teoria e o que ocorre na prática. Essa divergência também ficou evidente quando o assunto foi a realização de projetos públicos. Os gestores colaboraram com vários exemplos sobre como se dão esses processos na realidade do município, o que agregou bastante ao aprendizado dos estudantes.

Ainda em relação aos Direitos Humanos e Justiça, as oficinas direcionadas aos agricultores da região apresentaram o tema da participação social e fontes de financiamento, como o PRONAF, tendo o propósito de empoderar esses grupos através do incentivo à participação ativa em reuniões de conselhos municipais e à formação de parcerias, além do fornecimento de informações pertinentes ao processo de aprovação de financiamento de projetos. Os grupos foram bem expressivos e relataram grandes problemas para a execução de suas atividades, como a falta de assistência técnica da Emater, o que causa uma maior desmotivação para a busca de melhorias para o setor nessa região.

Para o eixo da Saúde foram preparadas ações que buscavam conscientizar a população para a tomada de medidas preventivas até o seu atendimento para um possível encaminhamento ao centro de saúde, em uma ação conjunta com a outra equipe. O Dia S de Saúde foi pensada pela IFES em análise e foi uma tarde destinada ao atendimento dos moradores, sendo uma ação executada pelos estudantes da área da saúde presentes na equipe desta IFES e da equipe de uma 
Do gabinete à comunidade: a experiência do Projeto Rondon na formação profissional no campo de públicas

outra IES. Ao medir o peso, a pressão arterial, a circunferência da cintura foi possível orientar a população sobre as questões e doenças relacionadas à obesidade (e sobrepeso) - visto que a obesidade é um problema que foi identificado na cidade. Assim, fornecemos algumas informações e dicas nutricionais. Quando necessário fez-se o encaminhamento de algumas pessoas ao posto de saúde para uma verificação mais acurada pelos profissionais de saúdas do município.

Essa atividade foi seguida de uma ação que teve como foco a mobilização da população em relação à poluição do Rio Paraíba, que passa pelo município. O Funeral do Rio, uma passeata fúnebre que carregava um caixão, foi uma proposta para mostrar que a situação de degradação do rio necessita de uma mudança no hábito das pessoas para que essas não descartem o seu lixo nesse local. As equipes conseguiram chamar a atenção dos moradores, que mostraram ter a consciência, durante o contato perante a realização de outras ações, de que a situação calamitosa do rio causa sérios impactos em sua na saúde.

Os rondonistas elaboraram um calendário no qual inseriram informações referentes à prevenção de certas doenças como a diabetes e a esquistossomose para ser distribuído às famílias em visitas realizadas às comunidades que necessitavam das informações constantes naquele documento. Além disso, também foi produzido e distribuído um jogo educativo para as crianças aprenderem a se prevenir em relação à algumas doenças de uma forma divertida e interativa. Foi realizado um dia de recreação, quando os rondonistas a ensinaram a jogar e promoveram várias outros jogos e atividades. A ideia destes dois documentos distribuídos aos moradores era transmitir o conteúdo de maneira mais lúdica e menos técnica (palestras e termos técnicos).

Ainda trabalhando o eixo de Saúde, foi preparada para os adolescentes uma oficina que tratou do tema das drogas e da gravidez precoce. Um labirinto foi montado em uma sala escura e, utilizando uma lanterna, os rondonistas foram mostrando aos participantes como eram prejudiciais as consequências de se deixar levar por um vício em drogas e da não utilização de preservativos nas relações sexuais.

Já em relação ao eixo Educação, os professores tiveram a oportunidade de participar de uma oficina sobre a diversidade sexual. A equipe trabalhou a questão de como abordar a orientação sexual na sala de aula e discutiram aspectos dos Parâmetros Curriculares Nacionais (PCNs). Foi possível perceber uma cautela em relação a abordagem do tema nas escolas, devido à outras questões presentes no município: o abuso sexual infantil e a questão religiosa, que influenciam diretamente a postura dos professores. Apesar disso, alguns deles demonstraram interesse pelo assunto e foram encorajados a refletir suas posições em sala de aula e não ignorar o assunto quando questionados por alunos. A ideia da oficina era discutir o fato de que os alunos 
Do gabinete à comunidade: a experiência do Projeto Rondon na formação profissional no campo de públicas

não deixam suas sexualidades do lado de fora da sala de aula e que em qualquer aula (não apenas a de Ciências) é possível abordar questões daquela temática.

A sustentabilidade também foi discutida em mais uma oficina direcionada aos gestores e servidores: da administração municipal. Especificamente em relação ao setor público, às instituições têm conceituado a Responsabilidade Socioambiental - RSA - a partir da abordagem ampla e conjunta que envolva os três pilares da sustentabilidade: social, ambiental e económico. Os rondonistas trabalharam os conceitos acerca da sustentabilidade, distribuíram um bloco de anotações elaborado pelos mesmos utilizando o verso de folhas que seriam descartadas pela IES;

A Agenda Ambiental da Administração- A3P, instrumento orientador do Ministério do Meio Ambiente foi a ferramenta utilizada pelos discentes como referência na oficina, a fim de sensibilizar e conscientizar os agentes públicos de Salgado de São Félix..

Os servidores deram vários exemplos de problemas relacionados ao desperdício de recursos no setor de trabalho e no município, como o uso excessivo de energia elétrica em uma escola municipal devido à uma questão técnica. Também problematizaram sobre o quanto é difícil implementar ações dentro do setor público que contribuam com o meio ambiente como, por exemplo, a diminuição do uso de papel e do desperdício de energia elétrica. A mudança de hábitos e a ausência do entendimento da procedência ds recursos públicos como sendo de todos, foram apontados como algumas das causas.

Conscientizaram que pequenas atitudes quando realizadas cotidianamente podem minimizar os impactos negativos nas ações diárias. A redução do consumo de bens e produtos, o uso eficiente da agua e energia elétrica, o condicionamneto e descarte adequado e coleta seletiva, dentre outras foram abordadas na oficina.

Ao final da oficina, os agentes se colocaram como multiplicadores e pontuaram possíveis ações que levariam a mudança de hábitos não apenas para o setor de trabalho como também no seu dia a dia. Dentre as propostas, a de divulgar a oficina e levantar o tema na rádio comunitária, como um dos canais para promoção da Educação Ambiental no município, foi executada logo após o encontro.

A Cultura, o quarto eixo, foi promovida por meio de diversasações durante as duas semanas de projeto, com música, dança, pintura e literatura. Por exemplo, as crianças e os adolescentes se reuniram em uma tarde na praça da cidade para aprender a tocar alguns instrumentos com os rondonistas, manuseando os instrumentos e aprendendo seus primeiros acordes, o que as deixaram muito animadas. Em outra tarde, o muro do Estádio Municipal foi reservado para ser pintado pelas crianças. Os rondonistas deixaram alguns desenhos e frases de conscientização sobre a poluição do rio, o uso de drogas, educação ambiental, entre outros, para 
Do gabinete à comunidade: a experiência do Projeto Rondon na formação profissional no campo de públicas

que as crianças pudessem pintar. Também foi elaborado um livreto em forma de cordel sobre a luta de Alagamar, que é uma comunidade rural situada na região e que tem uma importante história que parecia estar se perdendo no decorrer dos anos entre as novas gerações. Esse material foi distribuído para a população durante o projeto para estimular o resgate da cultura local.

Uma oficina de ballet foi oferecida para as crianças durante 09 encontros, com média de 24 crianças por encontro. Com o objetivo de incentivar o exercício da criatividade e a concentração, os participantes puderam conhecer alguns itens básicos do ballet clássico e se dedicaram para criar uma apresentação para o I Festival Gastronômico e Cultural do município. Nesse festival, realizado no último dia de projeto, estiveram presentes artistas locais como músicos, grupos de dança e mulheres que exibiram seus artesanatos. Para promover a cultura local, foi criado um concurso cultural, nas modalidades de dança, canto e redação. Os adolescentes criaram coreografias para apresentações de dança e um dos grupos se vestiram a caráter de Maria Bonita e Lampião. Também ocorreram apresentações de canto e distribuição de trofeus.

Em sua última oficina, os rondonistas apresentaram aos gestores diversas questões, dentro do contexto do município, que foram observadas durante as duas semanas de implementação do projeto. Naquela reunião que envolveu o prefeito e os secretários foi apresentado nosso feedback ao município, sendo discutidas nossas percepções sobre as possibilidades de outras ações que poderiam ser pensadas pelo município. Em outras palavras tentamos problematizar ações relevantes e carentes de atenção pelos tomadores de decisão daquele município. Por exemplo, discutiu-se a necessidade de um maior cuidado à saúde bucal da população, a urgência da educação ambiental na esfera pública e nas escolas, a importância de uma maior participação social e da formação de parcerias, a imprescindível cautela em relação à violência sexual infantil e a ausência da oferta dos serviços técnicos da Emater aos agricultores. O público presente na reunião colaborou com várias informações pertinentes e ajudou a formar discussões acerca das possíveis soluções para os problemas salientados.

A realização do diagnóstico dos problemas presentes na região serviu de grande aprendizado para os universitários, não somente para a elaboração do projeto e para a criação das ações que contou com a viagem precursora, mas, também, para o seu aperfeiçoamento durante a implementação. O feedback oferecido ao município colaborou para a visibilidade e discussão de muitos problemas vivenciados pela população em seu cotidiano, que talvez passem despercebidos, mas que carecem de soluções primordiais para a melhoria na qualidade de vida dessas pessoas. 
Do gabinete à comunidade: a experiência do Projeto Rondon na formação profissional no campo de públicas

\section{CONSIDERAÇÕES FINAIS}

Sendo o Campo de Públicas uma área de conhecimento voltada também para se discutir e buscar soluções para os problemas públicos, faz-se necessário que os futuros Administradores Públicos tenham consciência dos desafios que enfrentarão no futuro, sendo, assim, as estratégias extensionistas na graduação um conjunto de ações que possibilitam o entendimento da dinâmica e complexidade da atuação dos futuros gestores públicos. A busca pelo bem estar da população é um dos principais desafios para este profissional, devendo este buscar um alinhamento entre teoria e prática, de forma que possa conhecer a realidade da população, principalmente dos grupos que se encontram em situação de maior vulnerabilidade. Essas experiências são ricas para os futuros gestores pelo fato de envolverem um contexto complexo e dinâmico em que os cidadãos se encontram.

Por isso, a participação no Projeto Rondon como apresentado aqui neste estudo de caso nos mostra que este futuro profissional teve a oportunidade de vivenciar diversas realidades aplicando na prática todo o ensinamento adquirido na graduação por meio de elementos presentes na matriz curricular do curso aqui analisado. Como foi apresentado, um conjunto de disciplinas técnicas presentes na matriz curricular de um curso do Campo de Públicas auxiliou os discentes a elaboraram o projeto e a criarem ações pensadas em eixos como Saúde, Cultura, Educação, Direitos Humanos e Justiça que contribuíssem para o desenvolvimento de uma cidade no interior do estado da Paraíba.

No caso em questão, o sucesso na aprovação da proposta, de deu de forma clara, primeiramente pelo esforço e dedicação de discentes e docentes, contudo, os conhecimentos adquiridos na IES deram a estes alunos as ferramentas necessárias para obterem êxito na aprovação do projeto, levando-nos a crer que o curso de Administração Pública está, de certa forma, formando profissionais competentes e engajados com as causas sociais. Isso demonstrou, no caso do Projeto Rondon aqui apresentado, que houve um preparo técnico para concorrer, inclusive, com professores doutores e mestres de outras instituições que mandaram suas propostas e que não foram aceitas.

Este trabalho apresenta algumas limitações. A primeira delas diz respeito ao fato de ser um estudo de caso descritivo elaborado pelos participantes, sendo que não houve uma distância entre objeto de estudo e o processo de elaboração do relatório da pesquisa. Ao mesmo tempo, por se tratar de um estudo de caso, não se podem generalizar as experiências aqui apresentadas para os cursos do Campo de Públicas e nem para outros editais que a instituição possa concorrer. Entretanto, tais limitações não desmerecem o trabalho de investigação aqui apresentado uma vez que este artigo apresenta sua relevância para o Campo de Públicas ao: (i) discutir a Extensão 
Do gabinete à comunidade: a experiência do Projeto Rondon na formação profissional no campo de públicas

Universitária em uma área de conhecimento que está se consolidando em termos de ensino, pesquisa e extensão; (ii) evidenciar a aderência da matriz curricular de um curso às possibilidades e demandas do mercado e da atuação do futuro profissional do Campo de Públicas; (iii) sistematizar as experiências de ações extensionistas na busca de motivar (indiretamente) outros profissionais do campo.

\section{REFERÊNCIAS}

BRASIL. Plano Diretor de Reforma do Aparelho do Estado, 1995.

(2014b). RESOLUÇÃO Nº 1, DE 13 DE JANEIRO DE 2014. Institui as Diretrizes Curriculares Nacionais do curso de graduação em Administração Pública, bacharelado, e dá outras providências.

DECRETO No 62.927, DE 28 DE JUNHO DE 1968. Institui, em caráter permanente, o Grupo de Trabalho "Projeto Rondon", e dá outras providências.

BRESSER-PEREIRA, L.C. Reflexõoes Sobre a Reforma Gerencial Brasileira de 1995. Revista do Serviço Público, 50. 1999.

COELHO, F.S. A problemática atual do ensino de graduação em Administração Pública no Brasil. Cadernos EBAPE,2008.

CRUZ, B. de P. A., MELO, W. dos S., MALAFAIA, F. C. B. e TENÓRIO, F. G. Extensão Universitária e Responsabilidade Social: 20 anos de Experiência de uma Instituição de Ensino Superior. Revista de Gestão Social e Ambiental, v. 5, n. 3, 2011, p. 03-16.

FLANKLIN, C.B. Segurança e Defesa na Amazônia . UNB, 2012.

FOLTRAN, E.P; PISACCO, N.M.T; FOLTRAN JUNIOR, D.C. Extensão Universitária e Articulação de Saberes: a proposta do LALUPE - Laboratório Lúdico Pedagógico. Revista Conexão UEPG, 2009.

GRAÇA, M.S; PAIS, S.B. Um Espaço Para a Experiência Prática no Ensino de Graduação: O Caso da Criação da Qualitas, a Empresa Júnior da Facamp. VI SEMEAD - Seminários em Administração. São Paulo, USP, 2003. 
Do gabinete à comunidade: a experiência do Projeto Rondon na formação profissional no campo de públicas

MORANI, C. do N.S. As universidades e o Regime Militar. Revista da Faculdade de Serviço Social da Universidade do Estado do Rio de Janeiro, 2014.

MOTTA, R. P. S. As universidades e o Regime Militar: cultura política brasileira e modernização autoritária. 1. ed. Rio de Janeiro: Zahar, 2014.

NOGUEIRA, M. das D. P (org.) Extensão Universitária: diretrizes conceituais e políticas (Documentos básicos do Fórum nacional de Pró-Reitores de extensão das universidades públicas brasileiras). Belo Horizonte: PROEX/UFMG, 2000.

OLIVEIRA, C. H. Qual é o Papel da Extensão Universitária? Algumas Reflexões Acerca da Relação entre Universidade, Políticas Públicas e Sociedade. Anais do $2^{\mathbf{0}}$ Congresso Brasileiro de Extensão Universitária. Belo Horizonte, 2004.

PAULA, A.P. P de. Administração Pública Brasileira Entre o Gerencialismo e a Gestão Social. Revista de Administração de Empresas, v.45, nº.1, 2005.

PIRES, V.; MIDLEJ e SILVA, S. de A.; FONSECA, S. A.; VENDRAMINI, P.; COELHO, F. de S. Dossiê - Campo de Públicas no Brasil: definição, movimento constitutivo e desafios atuais. Administração Pública e Gestão Social, 2014.

SANTOS, Boaventura de Sousa. Pela mão de Alice: O social e o político na pós-modernidade. $3^{a}$ ed. São Paulo: Cortez, 1997.

SANTOS, M. S. S.; MENDES, I. A. C. Projeto Rondon: a metodologia educativo-assistencial de trabalho do s estagiários universitários. Esc. Anna Nery R Enf, v.9, n.1, 2005.

SARAIVA, J. L. Papel da extensão universitária na formação de estudantes e professores. Brasília. Méd., 2007.

VERGARA, S. C.. Métodos de Pesquisa em Administração. São Paulo: Atlas, 2005.

VIEIRA, C.S. Extensão Universitária: concepções presentes na formalização, em propostas e práticas desenvolvidas na universidade Federal do Paraná (1968 - 1987). Universidade Federal do Paraná, 2014.

ROMANO, R A. Universidade: entre as luzes e os nossos dias. In: ROMANO, Roberto A. (Org.). A crise da Universidade. Rio de Janeiro, Revan, 1998. 
Do gabinete à comunidade: a experiência do Projeto Rondon na formação profissional no campo de públicas

RAMOS, A. G. A nova ignorância e o futuro da administração pública na América Latina. Revista de Administração Pública. Rio de Janeiro. 17 (1): 32-65. jan./mar. 1983a.

Administração e contexto brasileiro: esboço de uma teoria geral da administração. 2. ed. Rio de Janeiro: Fundação Getúlio Vargas, 1983b.

SERRANO, R.M.S. M. Conceitos de extensão universitária: um diálogo com Paulo Freire. Universidade Federal da Paraíba, 2010.

YIN, R. Estudo de Caso - Planejamento e Métodos. $3^{a}$ ed. Porto Alegre: Bookman, 2005. 